\title{
trabalhanecessário
}

issn: $1808-799 \mathrm{X}$

ano 5 - número 5 - 2007

ensaio

\section{LAS POÉTICAS COLONIZADAS DE AMÉRICA LATINA}

Eduardo Subirats

La ausencia de un proyecto intelectual frente a los dilemas del siglo veintiuno ha puesto a las humanidades en el sistema educativo académico norteamericano y global frente a un límite. Primero se barrieron los precarios espacios de reflexión bajo el slogan del "final de los grandes discursos". La crítica del logocentrismo y del eurocentrismo ha dejado intactos los constituyentes y las consecuencias de la razón instrumental, pero ha barrido del medio las tradiciones criticas del siglo 20 a titulo de daño colateral. En su lugar se ha impuesto un formalismo semiótico en cuyas redes intertextuales se diluye programadamente cualquier reflexión histórica y social, y cualquier referencia a la realidad ecológica y política global. Y todo ello se ha cumplido con el entusiasmo de una liberación virtual o fabulosa de sujetos transindividuales, banalidades hipertextuales y espectáculos transculturales, bajo las coloridas banderas del final del libro, la muerte del intelectual y una anticipación psicodélica de un tiempo histórico terminal. La eliminación de las teorías críticas modernas ha corrido pareja de la evaporación institucional de la teoría estética y la crítica literaria, y su suplantación por los "cultural studies".

Este panorama adquiere en el ámbito de los estudios latinoamericanos dimensiones chocantes. Para nadie es un secreto, en primer lugar, que la prosperidad de estos estudios en Norteamérica ha estado pautada por su creciente predominio hemisférico en un terreno tanto económico, como mediático y militar. El derrumbamiento del Imperio español y la ocupación estratégica del Caribe en 1898 habían señalado su comienzo, anticipado por la anexión militar de la mitad del antiguo territorio nacional mexicano. A lo largo de este 
proceso expansivo las lenguas portuguesa y española, hasta fechas recientes encerradas bajo las cláusulas decimonónicas de la Romanistik a título de extensión intelectualmente insignificante del francés y el italiano, han desplazado numéricamente en los campus académicos a aquellos, e inclusive al alemán, tradicionales baluartes de una tradición filosófica y literaria humanista e ilustrada que en el ámbito cultural ibérico nunca tuvo lugar. Por lo demás, la Guerra fría puso de manifiesto la importancia de ampliar los espacios académicos del latinoamericanismo a nuevos campos culturales que abarcaban desde los estudios alimentarios hasta las lenguas históricas de América.

La expansión de los estudios latinoamericanos e hispanísticos ha estado jalonada a su vez por una serie de cambios institucionales. Su expansión en los campus norteamericanos se tradujo primero en una preponderancia del español de España con arreglo a un concepto eurocéntrico que puso en escena la generación de intelectuales del exilio español de 1939. En la Universidad de Princeton se llegó al extremo de exigir, hasta una fecha relativamente reciente, el conocimiento de la lengua castellana como requisito para aprender el portugués. Y fue paradójicamente su más distinguido hispanista, Américo Castro, el mismo que cuestionó los principios constituyentes del nacionalcatolicismo español, quien formuló el concepto de una hegemonía moral y lingüística de España sobre Iberoamérica bajo criterios imperiales que no difería en lo fundamental de la unidad heroica y católica de la Hispanidad formulado años antes por el fundador del movimiento fascista y nacionalcatólico español, Ramiro de Maeztu.[1] Pero la decadencia cultural española que este mismo nacionalcatolicismo agravó, y el ascenso de una poderosa generación de intelectuales y artistas latinoamericanos que no tenía precedente ni paralelo en sus contrapartes peninsulares (excepto en la poesía ibérica, de Pessoa a Ramón Jiménez o Espriu, y en su pintura, con obras como la de Picasso) puso un rápido fin a esta desigual constelación.

La creación literaria de escritores como João Guimarães Rosa, Juan Rulfo, Augusto Roa Bastos o José María Arguedas, que trazaban un proyecto socialista y democrático dentro y fuera de sus respectivas obras literarias, por otra parte la innovadora actividad de críticos como Ángel Rama y Antonio Cándido, que eran al mismo tiempo intelectuales con un compromiso social ejemplar, y la renovadora obra ensayística de escritores como Carlos Mariátegui, Darcy Ribeiro, Eduardo Galeano u Octavio Paz, amen de compositores, artistas plásticos, cineastas y arquitectos de la mayor originalidad abrieron espacios nuevos en la cultura internacional $y$, en consecuencia, en los departamentos de Spanish\&Portuguese. $Y$ en esos espacios se generaron una pléyade de estudios y obras de referencia que tenían por denominador común una preocupación hermenéutica, una voluntad de rescate de memorias perdidas y una voluntad crítica en lo simbólico como en lo político, que les permitía establecer una relación de afinidad y solidaridad con sus colegas del Sur. Las obras de John Murra, William Rowe y Rolena Adorno en los Estados Unidos, o la de Martin Lienhard en Europa, para referirme solamente al área específica del los estudios andinos, pueden citarse a este respecto como un trabajo de crítica literaria, 
investigación antropológica y análisis político estrechamente ligado a los debates intelectuales latinoamericanos sobre colonialismo y neocolonialismo, teología de la liberación y las estrategias de resistencia democrática y antiimperialista.

Quiero llamar la atención sobre un aspecto central del pensamiento a la vez estético y político de esta generación de intelectuales. $Y$ para ello quiero señalar una obra que difícilmente puede pasar desapercibida, aunque hoy sea globalmente ignorada: la de Oscar Niemeyer. La cuestión que quiero subrayar a este propósito es la definición de un proyecto intelectual y artístico de soberanía cultural y política en el medio de la arquitectura y el urbanismo a partir de los constituyentes históricos y las tradiciones culturales de América latina. La crítica arquitectónica norteamericana y europea nunca perdonará a este respecto que Brasilia la construyeran tres grandes genios, Lucio Costa, Oscar Niemeyer y Roberto Burle Marx, en lugar de subordinarse a las exigencias corporativas de las grandes agencias del Norte, que de todos modos la sometieron militarmente al día siguiente de su inauguración. Y tampoco perdonarán que el Memorial de América latina de São Paulo se levantase, dos décadas más tarde, precisamente en el momento álgido de la colonización mediática y financiera de América latina, cuando el "postmodern" y el "global" entraban en ebullición a través de las redes corporativas de comunicación. Quiero acentuar, además, que esta formulación artística de un proyecto social abierto sobre la base de una tradición cultural latinoamericana no era ni es solamente, ni en primer lugar, política.

Niemeyer, como lo hiciera antes el poeta Oswald de Andrade, y más tarde la arquitecta Lina Bo, no dejó de plantear una cuestión radical que la crítica norteamericana y europea ha querido soslayar: la crisis, el fracaso y la bancarrota de los proyectos mas innovadores, en lo social como en lo formal, de las artes y la arquitectura a partir del momento en que los fascismos europeos tomaron el mando, desencadenando la llamada Segunda guerra mundial. Para estos intelectuales, lo mismo que para otros artistas latinoamericanos como Juan O'Gorman y Diego Rivera, la exposición del International Style organizada por el MOMA en 1937 y el libro homónimo de Henry-Russell Hitchcock y Philip Johnson no significaron otra cosa que el anquilosamiento académico, la rigidez dogmática y la imposición normativa de lo que en las primeras décadas del siglo 20 había sido un ensayo de innovación, y una experimentación a la vez social y formal, en las obras de arquitectos como Loos o Gropius, y en las poéticas de Tzara, Schoenberg o Klee.[2]

Pero lo mas importante en los proyectos de estos arquitectos, y lo más destacable en escritores como José Maria Arguedas, Darcy Ribeiro o Augusto Roa Bastos no era solamente la crítica de este cristalización academicista del movimiento moderno en un "estilo", y los valores de puritanismo e imperialismo que el proyecto de su globalización entrañaba precisamente en el momento en que daba comienzo la hegemonía nuclear y económica global de los Estados Unidos. El proyecto artístico e intelectual que todos ellos formulaban partía de una integración lingüística, simbólica y al mismo tiempo social de las culturas populares de América latina (que son sus culturas históricas); y partía asimismo de la configuración de un estado democrático soberano con respecto a los poderes 
económicos y tecnológicos del Primer mundo, que fuera, además, capaz de asumir las responsabilidades de una distribución justa de las riquezas de la región, y la constitución de una elite intelectual independiente como fuerza culturalmente dinamizadora. Baste recordar los estudios sobre música popular de Mario de Andrade o de José Maria Arguedas, los artículos sobre los problemas sociales y culturales de los mayas por parte de Miguel Ángel Asturias, la crítica de los constituyentes políticos del hambre en América latina por Josué de Castro, la reforma de la concepción del indio mexicano por parte de Guillermo Bonfill Batalla, o los proyectos de educación y cultura popular formulados por Darcy Ribeiro, a título de citas de este vasto proyecto intelectual y artístico de una civilización latinoamericana.

Coronó este florecimiento social e intelectual algo que conocemos o quizás no conocemos: golpes militares internacionalmente amparados, destrucción de organizaciones sociales democráticas y populares, la persecución, tortura y asesinato masivos de intelectuales y lideres sociales, y una irreversible regresión regional en todos los aspectos de la vida humana. Lo que se impuso sobre aquel florecimiento cultural latinoamericano, que simbólicamente cristalizó en la Revolución cubana en un extremo y en la construcción de Brasilia en el otro, fueron los fascismos latinoamericanos de la segunda mitad del siglo 20. Es significativo que se suela desplazar el análisis político de estos fascismos en provecho de una mirada academicisticamente engalanada 0 simplemente burocrática sobre intangibles derechos humanos a despecho del hecho de que, desde la edad colonial clásica, esos derechos han fungido de todas maneras como moderador jurídico de los sucesivos genocidios americanos.

Pero no solo se han despolitizado los golpes de estado y las estrategias globales genocidas de esos fascismos latinoamericanos en nombre de etéreos sujetos jurídicos. $Y$ no sólo sus constituyentes militares y económicos se han transubstanciado en sutiles representaciones de género. Al mismo tiempo, se ignoran militantemente dos de sus pilares fundamentales: por una parte, la persistente herencia colonial hispánica en las tradiciones religiosas, politicas y militares, su inseparable hibridación de autoritarismo brutal, violencia y explotación sexuales, y atraso intelectual, que ha prevalecido a lo largo de la historia iberoamericana (e ibérica) con brevísimas interrupciones; y, no en último lugar, la ausencia de las grandes rupturas que dieron forma a las culturas modernas - la reforma cristiana, el humanismo secular, la ilustración, el liberalismo burgués y las propias revoluciones socialistas que marcaron el destino de Europa y Norteamérica; y en segundo lugar, los imponderables tecnológicos y tecnocráticos del nuevo colonialismo industrial y postindustrial global.

La generalización de constituciones democráticas en la Península ibérica e Ibero América en las últimas décadas del siglo pasado bajo los auspicios de aquellos mismos poderes regionales y globales que habían sostenido los regímenes autoritarios precedentes fue, sin duda alguna, el final feliz que concluyó largos años de terrorismo estatal. Pero el tiempo no había pasado en vano y, mientras se ajustaban las cuentas del 
cambio democrático en la región, también la democracia había cambiado en cuanto a sus nuevos instrumentos electrónicos y su nuevo vacío social. Ya no era el proyecto político que había impugnado el conservadurismo global y los fascismos locales de los años sesenta. Se trataba ahora más bien de un sistema global, de una globalización democrática o de la democracia postmoderna global, o del postmodern tout court como nuevo sistema jurídico, financiero y cultural globalmente uniformado. Es importante señalar, sin embargo, que el modelo transicional de las dictaduras fascistas a esas nuevas democracias lo canonizó la cuna imperial de Ibero-América: la Monarquía hispánica. Y que el significado ejemplar de esta transición española puede resumirse como un cambio que no puso en cuestión, ni jurídica, ni política, ni intelectualmente ninguno de los constituyentes de aquello que supuestamente debía de cambiar, o sea, el primitivo autoritarismo nacionalcatólico y fascista. Fue además un cambio que supuso la disolución de la imaginación crítica de los anos sesenta y setenta en las semiologías del espectáculo postmoderno.[3]

Esta doble conversión de las democracias postmodernas tuvo una serie de consecuencias. En el plano simbólico significó la volatilización de la cultura como espacio de reflexión y transformación sociales, en provecho de un concepto administrado de cultura como sistema semiótico comercialmente subordinado. Y ello significaba que el mismo intelectual o artista que había sido liquidado por la violencia fascista en los años sesenta se disolvía ahora en el aire de la acción comunicativa y sus monopolios corporativos de las décadas postmodernas que le siguieron.

"Ideas fuera de lugar" y el intelectual como "letrado" fueron dos de las protestas más relevantes, debidas respectivamente a Roberto Schwarz y Ángel Rama, contra la integración de los intelectuales latinoamericanos de oposición en las burocracias de una cultura administrada.[4] Schwarz ridiculizaba al charlatán que citaba a Sartre en las fiestas políticas protagonizadas por las autoridades golpistas de Brasil, y Rama ponía de manifiesto la continuidad del intelectual colonial como hombre de leyes y el moderno administrador de las modernidades colonizadas. Pero las transiciones democráticas finiseculares hicieron algo más que refundir el intelectual reformista en los moldes de la acción comunicativa corporativa y académicamente vigilada. Lo que en rigor se transformó no era la condición del intelectual subalterno de corte colonial, autoritario y burocrático, sino los nuevos marcos y diseños institucionales, y las nuevas jergas académicas que amparaban su tradicional mediocridad. Rede Globo y Televisa, los consorcios editoriales internacionales y las corporaciones académicas globales se impusieron inmediatamente como sujetos de una opinión pública formateada y como agentes administrativos de una sociedad civil electrónicamente movilizada. Y ya no hacía falta izar la ominosa bandera de la patria, la familia y la propiedad para legitimar poderes políticos antidemocráticos, allí donde las retóricas de un feminismo y un multiculturalismo académicamente enlatados generaban mejores consensos de legitimación estadística. En el nuevo orden global de la democracia como espectáculo ya no había "ideas fuera de lugar" en el sentido en el que 
las había criticado Schwartz, pero sólo porque ya no había lugar para las ideas, y "el final de la ciudad letrada" se ha celebrado con inconfesado cinismo en la academia norteamericana bajo los emblemas triunfantes de culturas hibridas integralmente domesticadas bajo las normas de los malls comerciales y los cultural studies .

Estos cambios han sido jalonados y en muchos aspectos alineados por transformaciones estructurales de las perspectivas teóricas, y de los programas de investigación y enseñanza. Allí dónde se reformulaba la democracia como artefacto, allí también se redefinía la cultura como performance, y allí se reconvertía la literatura y el arte en "social text", para empaquetar finalmente sus residuos degradados bajo las vigiladas fronteras postnacionales del "Hemisferio occidental".

Algunos detalles de estas estrategias de conversión a la vez semiótica y geopolítica son dignos de tenerse en cuenta. $\mathrm{O}$ al menos es digno de tenerse en cuenta la primera y absoluta condición de este vasto proyecto hemisférico de homologación cultural y vigilancia académica: la liquidación comercial de las tradiciones literarias y artísticas nacionales, y la evaporación lingüística del intelectual como conciencia reflexiva y mediación autónoma de una opinión publica democrática de escala regional y global. Este proceso de depuración fue, ciertamente, una operación paradójica y compleja, si se tiene en cuenta que se ha ejecutado y sigue siendo monitoreada a partir de departamentos universitarios que exhiben la bandera de las humanidades. Pero la comparación con la práctica antihermenéutica de deconstruir a los dioses americanos para hibridizarlos a continuación como santos católicos llevada sistemáticamente a cabo por corporaciones religiosas globales en la edad del colonialismo clásico puede resultar clarificadora en este contexto.

En mi ensayo Viaje al fin del Paraíso. Siete Visiones de América latina, pongo de manifiesto la relación de continuidad y complicidad entre el proceso político de liquidación de la intelligentsia latinoamericana a través del genocidio y el exilio, y su subsiguiente evaporación textual a través de su conversión en entertainment mágicorealista tutelado por la industria cultural, y en objeto de las corrientes entomologías académicas. Por lo demás, estas rebajas del universo o universos intelectuales latinoamericanos se han afianzado a través de una serie de soberbias categorizaciones. Así, lo que en realidad es el canon clásico moderno de la literatura latinoamericana se ha subsumido a las etiquetas del boom, el preboom y el postboom, algo que nunca he sabido si es una alusión a bombardeos militares o campañas de ventas de saldo. Pero es esta efectiva campaña de reconfiguración comercial académicamente formateada del canon literario latinoamericano bajo el package de realismo mágico el efecto más prodigioso de esta mutación de la cultura literaria latinoamericano en entertainment de la industria editorial. Por lo demás, debe señalarse, aunque solo sea entre paréntesis, que esta marca realmaravillosa debe su irrebatible éxito publicitario a la circunstancia un tanto oscura de que nunca se haya debatido rigurosamente su concepto, ni con respecto a la crítica artística alemana de los años veinte del siglo pasado que lo inventó, ni mucho menos en el latinoamericanismo de 
la otra mitad de siglo que lo globalizó.

Con todo es preciso subrayar que estas categorías comerciales de la crítica literaria corriente son lo más conspicuo que se puede encontrar en los festivales literarios. Pero no es lo más excelente. La versión respetable del travestimiento realmaravilloso de una literatura que sin embargo se distingue, como en los casos de Juan Rulfo, Augusto Roa Bastos y José María Arguedas, por su profundidad mitológica, metafísica y ética, amén del proyecto político que las atraviesa, lo ofrecen los cultural studies. Llamar a estos estudios culturales una sociología literaria no sería muy generoso puesto que esta Erkenntnissoziologie, en el sentido en que la concibieron Emile Durkheim y Karl Mannheim, partía de todos modos de un concepto sistemático de sociedad y una articulada critica de las epistemes tecnocientíficas. Y, definitivamente, éste no es aquí el caso. Pero lo que realmente define a esos estudios y les otorga su vigor institucional no reside solamente en este carácter metodológicamente vaporoso, sino en su definición como territorio departamentalmente vigilado, con un dentro y un afuera, unas reglas de juego predefinidas, unos árbitros epistémicos y el correspondiente sistema solapado de censuras políticas.

Pero no es eso tampoco lo más importante. Lo que debe señalarse desde la perspectiva de una historia mínima de las ideas es que bajo su coqueto paraguas interdepartamental este campo de estudios culturales funge como el cementerio de desguace y desactivación de las teorías críticas del siglo veinte. Su celebradas semiologías de género, el tan traído y llevado multiculturalismo y sus dulces sueños hibridistas han tenido una elocuente función: prosopeya de amansamiento académico y moderación intelectual de las guerras y conflictos entre los sexos, los choques culturales y la colonización semiótica que atraviesan la expansión global de la cultura industrial moderna y postmoderna. El objetivo final de este piadoso travestimiento de los procesos de desmantelamiento cultural y social reales y efectivos de nuestrom tiempo no es menos piadoso: el secuestro de la intencionalidad intelectual, la domesticación y neutralización del compromiso histórico y político de la crítica, y la volatilización de la voluntad práxica de transformación real indisolublemente ligada a toda obra literaria y artística. No tengo que subrayarlo más: el significado de estos estudios sobre la cultura es enteramente regresivo. Pero todavía tengo que añadir un comentario más.

Bajo las insignes consignas de una figurada superación del antropocentrismo y el logocentrismo estos estudios culturales han confundido patéticamente la crítica del sujeto racional de la dominación, en su figura lógico-trascendental o en su figura política imperial (el Je cartesiano o el Leviathan de Hobbes), así como de sus antecedentes mitológicos patriarcales, con lo que ha sido la gran tradición filosófica e intelectual que, de Friedrich Nietzsche a Oswald de Andrade y de Johann Jakob Bachofen a Eduardo Galeano, ha abierto los caminos de su critica. Protegidos por la algarabía que semejante ambigüedad genera, estos mismos culturalistas han incautado complementariamente el valor a la vez artístico y creativo de la forma, así como el significado ejemplar que toda obra literaria 
entraña como proceso formativo: en el doble sentido de dar forma a una realidad y formarse a través de su experiencia. La última consecuencia de este pirateo es la eliminación de la experiencia estética y el sacrificio ritual de la autonomía de la obra literaria y artística, lo que, finalmente, redunda en su saqueo como material textual de procesamiento semiótico bajo cualesquiera procedimientos pseudosociológicos. Los resultados de este procesamiento son apurados: hoy en los departamentos literarios norteamericanos no se hace crítica literaria; mucho menos todavía teoría critica de la sociedad.[5]

Una anécdota puede ser, a este respecto, más elocuente que mil palabras. José Maria Blanco White ha sido un escritor español maldito. Contestó la Inquisición, puso de manifiesto la corrupción moral e institucional de la Iglesia católica española del siglo dieciocho y escribió una serie de ensayos teológicos de signo reformista que nunca se han publicado en español. Pero también puso de manifiesto las limitaciones y precariedades del lado de la oposición, o sea, de los liberales hispánicos, y lo hizo con la misma desenvoltura con que atacó los valores del tradicionalismo católico y la depravación de la máquina inquisitorial. Por si ello fuera poco en el páramo intelectual hispánico, Blanco tomo cartas a favor de la independencia hispanoamericana. $Y$ aun se atrevió a cuestionar las ambigüedades y traiciones con respecto a la herencia colonial que muchos de los líderes de la independencia latinoamericana, Servando Teresa de Mier entre ellos, acataban en la letra pequeña de sus confusos programas políticos. Todos estos rasgos hacen de Blanco la figura intelectual más sobresaliente en el contexto de la fracasada revolución liberal española y la maniatada independencia latinoamericana. Pero son también muy buenas razones para que el tradicionalismo católico haya denostado su obra durante dos siglos, hasta enterrarla en el olvido. A falta de hogueras, Menéndez Pidal pronunció una sentencia inquisitorial post mortem en contra de Blanco White y su nombre desapareció prácticamente sin huellas de los cánones literarios de un hispanismo cuya característica más notable ha sido su desinteligencia.[6] Quizás deba considerarse por eso un milagro que, en los años sesenta del pasado siglo, otros dos exiliados asimismo ninguneados, Vicente Lloréns y Juan Goytisolo, emprendieran desde la Universidad de Princeton la rehabilitación no solo de su memoria, sino de su proyecto pendiente de reforma intelectual y política de las culturas hispánicas.

Hoy las cosas han cambiado y no han cambiado a este respecto. Ciertamente, en los círculos intelectuales más escogidos la obra de Blanco ya no puede ser ignorada. Esgrimir en su contra los viejos prejuicios del catolicismo español ya solo serviría hoy para desenmascarar a sus renovados censores. Otras retóricas han tenido que generarse para renovar su censura. $Y$ ahí viene la anécdota en cuestión. En la misma Universidad de Princeton que había presenciado su reciente renacimiento, un prestigiado que no esclarecido hispanista condenó recientemente a este mismo Blanco White con un argumento feminista en torno a los embrollados secretos que compartía con las monjas que confesaba, y con el cuento todavía más destilado de unas ilícitas relaciones sexuales 
con una desconocida. La corriente mojigatería académica elevó a continuación su puritano chismorreo a veredicto, con el modesto propósito final de desalentar la investigación de la profesora Lunden Mann sobre el pensamiento religioso, político, filosófico y místico de Blanco White.[7]

No hace falta señalar que la supresión y superación del sujeto se ha convertido en un rito de tonsura académica en la edad posthumanista tan insoslayable para la reproducción institucional de su ceguera intelectual como la destitución de los grandes discursos o del pensamiento tout court que legitima. Esta destitución disciplinaria de los sujetos intelectuales se ha legitimado con gran alboroto como misión redentora de los sistemas panópticos de castigo y vigilancia inherentes a la constitución lógico-trascendental de la razón moderna. Lo que supone entre otras cosas una sublime indistinción entre la razón instrumental y la experiencia intelectual reflexiva. No obstante, la nueva conciencia corporativa se siente con las manos libres, en nombre de este ofuscamiento, para entregarse a las polivalencias metonímicas de las jergas deconstructivistas, que ya nadie escucha porque nadie entiende. La ventaja institucional de semejante embrollo consiste sin embargo en olvidar y hacer olvidar en los sistemas vigilados de enseñaza superior que la constitución del sujeto estético en una obra literaria como la de Augusto Roa Bastos o Juan Rulfo no tiene nada que ver con las fracturas y dilemas del sujeto cartesiano 0 kantiano, con sus derivados lógico-positivistas y fenomenológicos, y mucho menos con sus panópticos totalitarios, sino que su interés reside precisamente en sus dimensiones mitológicas, metafísicas y éticas profundas, que se han elaborado a partir de las voces de la memoria, de la experiencia de la agonía, y de un esfuerzo por encontrar un sentido y una salida a su voluntad de preservar su ser en los laberintos de los poderes globales y sus razones deconstructivas.

Pero el asalto a este sujeto estético, que es al mismo tiempo un sujeto social y cultural, y el sujeto de un proyecto intelectual y político que necesariamente entraña una crítica de los multifacéticos discursos de la colonización, tanto en sus figuras teológicas como seculares, trascendentales o estructuralistas, no es la única secuela del pillaje semiótico practicado por los estudios culturalistas. Su última y decisiva consecuencia política es la conversión antiestética de la cultura. Permítanme a este propósito un par de observaciones al margen.

En la tradición filosófica moderna han coexistido dos concepciones fundamentales de cultura. Una de ellas la representan los análisis filosóficos e históricos de Vico y Herder, y los grandes y pequeños nombres de la antropología y las ciencias de la religión, de J.J. Bachofen a Karl Kerény. Es la tradición que ha comprendido el origen y el desenvolvimiento de las culturas a partir de sus mitos, sus dioses y sus cosmogonías, concebidos como sistemas de integración de todas las expresiones humanas, ya sean productivas o materiales, ya sean estéticas o éticas, en un orden ontológico y religioso cuyo último sentido es la preservación del ser. Pero la tradición racionalista que ha predominado sobre la filosofía moderna concibió la cultura, por el contrario, a partir de la 
acción constituyente de un sujeto trascendental sin memoria (Kant), del trabajo productivo de un fabuloso homo oeconomicus (Mill) o de la acción formadora del no menos imaginario homo faber (Bergson). Y si la primera concepción estaba centrada en la preservación del ser a lo largo de ciclos cósmicos que integraban la historia del espíritu humano, la segunda definición de cultura ha girado en torno a los procesos de separación y abstracción epistemológica y social de la naturaleza y las memorias históricas, y de la subsiguiente subordinación de ambas.

Claro que estas dos concepciones han mantenido siempre relaciones secretas entre sí. La filosofía moral kantiana o la filosofía de la historia de Hegel trazaron puentes entre la racionalidad tecnocientífica y el sistema de una cultura moral y artística que recogía muchos de los caracteres de la cultura mitológica definida por Vico o Schiller. El socialismo del siglo diecinueve y los movimientos artísticos revolucionarios allegados a él, de Courbet a Gropius, también trataron de armonizar la techné industrial con un concepto ético y estético de lo social. Pero los sistemas de poder global desarrollados a partir de Hiroshima y Nagasaki han revertido estas tentativas de conciliación. La razón tecnocientífica, la razón productiva y la razón como sistema de dominación universal han acabado por liquidar la misma conciencia, y las mismas condiciones biológicas y culturales de supervivencia humana como ultimo baluarte de resistencia contra si misma. Múltiples son los planos de la realidad cultural global, desde la biodiversidad hasta la comunicación, que hoy ponen de manifiesto una situación mundial catastrófica e irreversible.[8] Dos obras centrales de la filosofía del siglo 20, la de Adorno y Horkheimer, así como la de Foucault, deben recordarse en este sentido como la expresión filosófica de esta disolución interior del orden civilizatorio y de su sujeto humano como premisa y consecuencia de su propio principio epistemológico y lógico de dominación.

Los cultural studies, lo repito, no son una teoría, ni siquiera una metodología científica propiamente dicha. Contemplados desde el punto de vista de la historia de las ideas deben considerarse más bien como los restos de este naufragio civilizatorio de la razón moderna. Habla de feminismo como performance, pero no es capaz de plantear los fundamentos mitológicos y ontológicos que definían el poder cósmico y el orden ético de las diosas de la vida y muerte en todas las culturas precristianas en un momento en que la ingeniería genética desplaza virtualmente las dimensiones reproductivas de la mujer y las dimensiones espirituales indisolublemente ligadas a ello. Esgrimen las semióticas y retóricas multiculturalistas y omiten al mismo tiempo su fundamento tanto biológico como económico a partir del cual un artista, un pueblo o una sociedad son capaces de crear y defender su individualidad cultural propia a través del comercio y el diálogo con lenguas, dioses y formas de vida diferentes. $Y$ levantan la bandera de un liberalismo humanitario identificado con las llamadas minorías étnicas y los denominados grupos marginales, pero sin cuestionar los constituyentes civilizatorios que distinguen a indios $u$ homosexuales como efectivos sujetos negativos, ni desentrañar aquellos conceptos de deseo, naturaleza y comunidad que objetivamente condiciona su marginación estructural bajo el orden 
capitalista y el logos colonial. Lo que Anke P. Böttcher formuló en una ocasión contra las retóricas del feminismo políticamente correcto - "quieren travestir a las gatas con vestidos de perro y se olvidan de que un perro que maulle siempre infundirá menos respeto que una gata bufando" - puede generalizarse a lo que los agentes de estos studies se complacen en llamar, con el gesto inconfundible de un comando militar, estrategias culturales.[9]

Pero lejos de ser un inconveniente hermenéutico, este travestimiento, y la consiguiente omisión de las condiciones materiales, los environments ecológicos y los nexos políticos reales en su concepto de género, comunicación, lietratura, arte o cultura constituye la gran ventaja institucional de estos estudios culturales. Su éxito reside precisamente en reducirlo todo, lo mismo el conflicto de sexos a lo largo de la historia de las religiones y del arte, que las guerras de resistencia anticolonial, a una lingüística plana, a una semiología formal o a la mise-en-scène de símbolos discrecionales. Al hibridismo lo definen como un collage icónico. Multiculturalismo es una performance. La política: acción comunicativa. Y la democracia, un espectáculo. El sujeto intelectual y estético es mutilado por fuerza mayor en sus dimensiones emocionales, existenciales, éticas y políticas, para elevarlo a la categoría superior de manager cultural y performer académico, y degradarlo al mismo tiempo al papel de consumidor de signos. Su abstracción de las condiciones materiales que generan los conflictos sociales y sus expresiones simbólicas le abren finalmente las puertas institucionales para poner en escena cualesquiera valores democráticos 0 banderas revolucionarias, y retóricas antiimperialistas, feministas 0 antirracistas, sin tener que molestarse en abandonar su sedicente paraíso semiótico de signos sin referente e intertextualidades sin substancia. De ahí también su última función misionera: suplantar la reflexión intelectual de un mundo en crisis por la producción y vigilancia de performances políticamente correctas.

Redefinir la literatura como estudios culturales significa anular el valor ontológico de la obra artística y el significado existencial de su experiencia. Pero también esto revierte en provecho de los culturalistas puesto que le permite igualar en su nombre a un anuncio multirracial de United Colors of Benetton con La Negra de Tarsila do Amaral, y proclamarlo muy progresistamente a los cuatro vientos como triunfo democrático del populismo comercializado del pop abanderado por la estupidez corporativamente patrocinada de Andy Warhol contra el elitismo estético de la aristocracia cafetera de São Paulo que ciertamente aplaudía las provocaciones del Movimento Antropofágico. En favor de esta piadosa conversión del arte en acción comunicativa se arguye que, al fin y al cabo, todo son representaciones, lo mismo la Guerra contra el mal que los video-clips de Madonna, y todo son repertorios de uno y el mismo código cultural. De ahí también la paradoja final que recorre los cultural studies como sublimación corporativa de la sociedad del espectáculo: su estetización indiferenciada de la realidad se da de la mano con la mutilación antiestética del valor mitológico, metafísico y ético de la forma artística. A fin de cuentas, La negra de Amaral se distingue de la basura populista del Pop-art por sus vínculos texturales y colorísticos con una tierra resacralizada bajo la potencia matriarcal de 
fecundación bajo la que el Movimento Antropofágico en la que se encuadraba concibió una revolución estética y política contra el logos patriarcal del colonialismo cristiano e industrial, frente al cual levantó, entre lujuriosas risas dionisiacas, la sexualidad salvaje de unos senos pletóricos que de todos modos el puritanismo semiótico que distingue a esos cultural studies prohibe tocar.

Por todo lo demás, la redefinición y reciclaje de la obra literaria y artística como performance cultural escamotea otro fraude trascendental: la inversión ontológica de la realidad que subyace al postmodern como sistema integral del espectáculo, lo cual ha permitido consensuar la producción industrial de performances y representaciones sociales como toda realidad y única realidad posible, y eliminar la experiencia individual y colectiva como un mundo ilusorio de delirios esquizofrénicos. En este proceso milagroso de mutación los estudios culturales han cumplido el mismo papel que el sacerdote que convierte pseudomágicamente el pan y el vino en la carne y la sangre de un dios global. Esta transubstanciación de la cultura en espectáculo, última consecuencia de la lógica que recorre a este logos deconstrucctivista, es al mismo tiempo expresión de la transfiguración mercantil de la realidad, así como de su reconfiguración institucional bajo las leyes y administraciones burocráticas del libremercado. Redefinir y rediseñar, reconstruir y reinstalar la literatura y la obra de arte como performance cultural es inseparable de su travestimiento como mercancía, entertainment y ficción de ficciones en un reino de simulacros sacerdotalmente administrado. $\mathrm{Y}$ esto explica finalmente la bagatelización de las humanidades en una academia intelectualmente vaciada dónde las literaturas se pueden clasificar graciosamente con arreglo a las mismas categorías sandungueras de tiranos, exilios, magias realistas o viajes de exploración que en los catálogos de paquetes turísticos, y en los que, del Porn al Pop, todo está permitido siempre que no plantee últimas o penúltimas cuestiones sobre el significado espiritual de la obra de arte o su importancia política como expresión de una voluntad solidaria de cambio hacia otro mundo posible y mejor: la dimensión metafísica y última de toda autentica experiencia artística de lo real.

Para acabar con estos comentarios sobre "la falta de espíritu de la universidad el día de hoy",[10] es preciso recordar algo, que debe definirse al mismo tiempo como última consecuencia y premisa institucional de las retóricas de la subalternidad y la diferencia, las semiologías del hibridismo o la transculturación, el feminismo de los signos y una banalizada homosexualidad, el multiculturalismo como performance y una defensa de los derechos humanos que de todos modos callan la boca frente a las practicas de exterminio que vemos todos los días en nuestras pantallas y en tiempo real. La premisa y a la vez consecuencia de esta uniformización semiótica de las expresiones culturales bajo las rúbricas de intertextualidades y performances es un nuevo orden geopolítico. A la conversión de las literaturas en semiotextos sociales le corresponde su reterritorialización burocrática en entidades tales como "América latina y el Caribe", "Hemisferio occidental", eje político-cultural "Norte-Sur", "Área Ibérica-Iberoamericana" o la demarcación geomilitar 
de un Atlántico Sur que comprenda los países de la costa Atlántica de África, la Península Ibérica, los Estados Unidos, y América latina y el Caribe en un cerrado dispositivo imaginario. Semejantes remapeos políticoculturales de América latina presuponen la suspensión de sus memorias históricas antiguas (las memorias populares precoloniales han sido homologadas a la categoría genérica de un sujeto subalterno tan global y maleable como las almas aristotélicas de los misioneros coloniales en su edad clásica) o modernas (los constituyentes de las independencias latrinoamericanas han sido volatilizadas y paralelamente suplantadas por las modernidades estéticas), la evaporación de la memoria de sus resistencias políticas y sociales, y, no en último lugar, la licuefacción de sus cánones literarios y tradiciones intelectuales en un reino virtual de textos, intertextualidades e hipertextos.

A este respecto debe recordarse una de las aficiones preferidas que han recorrido los estudios culturales anglosajones cuando los cañones de la Guerra fría comenzaron a enfriarse: los Border studies, las consiguientes retóricas de tráficos y tránsfugas semióticos, hibridaciones y pirateos icónicos, y los subsiguientes pasaportes transculturales. Esta obsesión por las fronteras, que recapitulaba el misticismo misionero de los pioneros coloniales de Nueva Inglaterra bajo terminologías ciertamente diferentes, se ha acompañado al mismo tiempo de una pasión antinacionalista, específicamente destinada a las fronteras y nacionalismos de los otros, o sea, de los postsujetos postcoloniales, pero que se travestía retóricamente con los colores más vivaces del internacionalismo anticolonial de África, Asia y América latina al mismo tiempo que disolvían sus constituyentes políticos en el océano del olvido.

También a este respecto la comparación histórica con las órdenes monacales resulta tan osada como ineludible. Sabido es que sus misioneros, cuando llegaban a un poblado indígena, obsequiaban cruces con la mayor generosidad. Para los hombres y mujeres de culturas erróneamente llamadas politeístas, que en realidad habría que denominar religiosas en un sentido mundano porque invisten sacralmente a todas las manifestaciones del ser ("Every part of the earth is sacred to my people"- escribió el Jefe Seattle al Presidente de los Estados Unidos), ningún objeto sagrado, propio o ajeno, es vano. $Y$ daban por bueno el obsequio. Pero, en una siguiente etapa, esos mismos misioneros advertían y advierten a sus indígenas, convertidos sin saberlo en acólitos, que la cruz no es un signo cualquiera, sino el gran significante que los contiene a todos por carecer de cualquier referente. A ella y solo a ella se le debe rendir el sacrificio de oro, sudor y lágrimas, al tiempo que se prohibía la experiencia y el sentimiento de lo santo con respecto a todos los demás objetos sagrados y a la naturaleza misma, por tratarse de manifestaciones maléficas del mismísimo diablo. Esta imposición misionera nunca puede tener efecto sin violencia, como en su día señaló Agustín. Violencia derivada de la reducción ontológica y la igualación semiológica de todas las cosas sagradas, desde el propio cuerpo humano hasta las animales, las plantas o las estrellas, a signos, cadenas significantes, alegorías y representaciones del gran significante Dios-Emperador. 
Hoy no se destituyen a los dioses, reducidos ya hace tiempo a cenizas. Tampoco se persigue a chamanes, que ya prácticamente no quedan. Lo que se hostiga con el mismo encono misionero de redefiniciones y reconversiones son sus memorias literarias y artísticas en el reino de la experiencia estética. De esta guisa se convierten a las diosas aztecas de Pedro Páramo en signos feministas de una estraegia identitaria deconstruccionísticamente desvalijada de entidad mitológica y sustancia ontológica. Así también se reconfigura la rebelión cósmica de las diosas de la tierra en el Abancay de Los ríos profundos que representan la chichera Felipa y la loca violada del convento de los frailes como representación de un sujeto subalterno sin memoria ni raíces ontológicas en el orden dinámico del ser increado e infinito de las cosmologías incas. Y si en su edad clásica el colonialismo convirtió a los dioses cósmicos de mayas y aztecas en santos híbridos, la reconversión global de estas tradiciones literarias y artísticas sirve hoy a la hibridación de fronteras, a las redefiniciones transculturales y a la refundición de un nuevo orden mundial sin memorias, sin dioses y sin ser.

[1] Américo Castro, Iberoamérica, su presente y su pasado (New York: The Dryden Press, 1941). Ramiro de $\Lambda$

[2] Eduardo Subirats, Viaje al final del paraíso. Ensayos sobre América latina (Madrid: Editorial Losada, 2005) pp. 40 y ss.

[3] He analizado las tosquedades y tropiezos de este "cambio" español en mi ensayo "De la transición al espectáculo", en: E. Subirats, Memoria y exilio (Madrid: Losada, 2003) pp. 345 y ss.

[4] Ángel Rama, La ciudad letrada (México DF: Editorial Fineo, 2007). Roberto Schwarz, Misplaced ldeas : Es

[5] Cf.: Eduardo Subirats, O Juizo Bufo/ El juicio bufo, en:

http://www.vitruvius.com.br/arquitextos/arq079/arq079_00.asp

[6] Hispanismo y latinoamericanismo son conceptos precariamente definidos que aquí utilizo como "equivalentes y desiguales". Cf. Eduardo Subirats "Siete Tesis contra el Hispanismo", en: Viaje al fin del Paraíso. Un ensayo sobre América latina, op.cit.

[7] Esta misma estrategias argumental, y aun otras más torpes, pueden leerse en las contribuciones de S. Kirkpatrick en el libro de ensayos sobre Blanco que yo mismo organicé hace unos años: Eduardo Subirats (compilador), José María Blanco White. Modernidad y exilio en la cultura española (Barcelona: Anthropos, 2005). Cf. Lunden Mann, Joseph Blanco White: An Intellectual Biography, 1776-1810 (PhD, Princeton, 2006)

[8] Me remito al análisis esbozado en: E. Subirats, La existencia sitiada (México: Fineo, 2007).

[9] Paula Böttcher, Genus Artis. Gesellschaftlichen Strukturen im Kulturkritik (Schloss Plüschow, 2000).

[10] Klaus Heinrich, "Zur Geistlosigkeit der Universität heute". En: K.H., der gesellschaft ein bewusstsein ihrer selbst zu geben (Frankfurt a. M: Stroemfeld Verlag, 1998), pp. 69 y ss. 
volta

file://C:IDocuments and Settings\AdministradorlMeus documentos\Minhas Webs\NED... 11/9/2008 